\title{
A Curricular Case Study: Constructing the Essential Factors in "Social Design" Teaching
}

\author{
Hui Hsin Cheng and Wen Huei Chou
}

\begin{abstract}
This study explores an innovative teaching approach based on the concept of social design. Using, as its case study, a design education course called "Social Design," currently taught in universities, this study discusses the essential elements of social design courses, based on the three characteristics of social-design education: design practices, problem evaluation, and interdisciplinary cooperation.

It concludes by showing that social-design education includes the following essential elements: 1) to train students to propose innovative solutions to problems; 2) to analyze problems comprehensively, on the scale of the socio-ecological-system; 3) to solve problems using interdisciplinary knowledge and understanding; 4) to include people who have experienced problems in the problem-solving process; 5 ) to ensure that students achieve reflective learning during the problem-solving process; and 6) to guide students in recognizing the "organic" nature of social design problems, in which levels of stakeholder participation affect problem-solving decisions, given that social systems are constantly changing.
\end{abstract}

Index Terms - Social responsibility of designer, social design, case study, design education.

\section{INTRODUCTION}

Most previous design studies have focused on ways to create commercial value or to satisfy the needs of the market, so as to achieve high quality designs that cater for our consumerist society. However, Papanek, in his book, Design for the Real World [1], proposed the concept of the social responsibility of the designer; he believed that design should do more than merely serve the market and he urged designers to consider the needs of disabled people, the ecological environment, hospital equipment, experimental research, and poor people in third-world countries [1]. Designers are duty-bound to respond to these social needs, as the creative nature and practical influence of designs can address many different social issues and serve a range of social groups [2], [3].

Margolin and Margolin have argued that commercially oriented design aims to satisfy market needs, whereas social design aims to fulfil social needs [4]. The ultimate goal of social design is to improve social quality [5]. Based on the historical development of design, social design can be discussed using three scales. The first is the design-for-wellbeing scale, which focuses on the core spirit of social wellbeing and stresses the pursuit of human wellbeing

Manuscript received January 9, 2019; revised June 13, 2019.

The authors are with Department of Digital Media Design, National Yunlin University of Science and Technology, Taiwan (e-mail: chenghh@qq.com, cristance@gmail.com). as its purpose. In other words, designers should use empathy to discern user needs, especially when working with underprivileged consumers who have been neglected by consumerist society in the past. Design should take into consideration the diversity among independent individuals [6], [7].

The second scale is designed for the public and based on the principle of universal design. Design should pay attention to the physical and mental status of each individual and be accessible to individuals with different characteristics in various environments [8]. When designing for the general public, designers should consider the needs of a range of different users, in order to benefit more minority groups. Emphasis is placed not only on physical convenience but also on achieving a higher level of social inclusion, in terms of mental health and psychological well-being.

The third type is design for the world. The complexity of social design problems calls for systematic thinking [9]. Ecological systems theory accommodates this characteristic and uses social systems as units. It posits that social systems are closely related to one another and maintain a dynamic equilibrium; also, the underlying environment will affect social systems at other levels [10]. In other words, social issues do not exist independently. Using ecological systems theory to evaluate social issues comprehensively can facilitate an understanding of social needs.

As social design involves complex problems and multifaceted stakeholders [11], traditional design education does not suffice to satisfy social needs [4]. More specifically, social-design education is highly experimental; to break through the education model of the past, educators must consider new ways of achieving transformation and innovation in the classroom context [9], [12], [13]. The problems of social structure are complex and require different fields and organizations to work together and use their expertise to look for solutions. Kolb, Kolb, Passarelli, and Sharma have proposed four teaching roles and nine student learning portfolios [14]. The roles of teachers and the learning styles of students must also be redefined. Social-design education consists of more than just the teacher and the students. To integrate interdisciplinary stakeholders, the Social Innovation Network (SIN) offers a new model of social-design education and organizes community partners, student teams, university faculty members and facilitators in the design profession, based on the scale of interdisciplinary educational activities, to promote the influence of social design projects and social-design education collectively [9].

In addition, Anand and Haag have proposed the Divergence-Convergence-Integration (DCI) technique as a social-design reference process [15]. DCI allows a design to 
adhere closely to complex social attributes and address actual current problems and needs; hence, it is a suitable topic of discussion for social design studies. In the classroom context of social-design education, teachers have to face not only students but also multi-stakeholders; the scale of the problem differs those faced by design education in the past. The present study therefore discuss the essential elements of social-design education, to provide a basis for future discussions and modifications.

The professional teams at universities possess new ideas, plans, and professional knowledge [16]. Integrating new things into communities through these teams can stimulate community development and transformation; using a bottom-up approach can facilitate the empowerment of local residents [17]. In the long run, these communities become self-sustainable, even when teams and other resources are taken away. Sustainable social development can potentially be achieved by such interventions.

In light of this, the present study discusses the essential aspects of innovative social design teaching, using as its case study a current course called "Social Design." The term "social design" is relatively new and often discussed in practical design fields. Nevertheless, few academic papers have defined the term strictly or implemented it systematically [4], [18]. To a certain extent, social-design education is highly experimental. This study aims to establish the essential elements of social-design education, helping teachers teach in more innovative ways.

The next section examines ecological systems theory, SIN, and DCI and analyzes social models using a curricular case study. It aims to define the essential elements of social-design education by analyzing a social design course.

\section{ESSENTIAL ELEMENTS OF SOCIAL DESIGN}

\section{A. Scale of Social Design}

Ecological systems theory postulates that humans are tightly connected with their physical and social environment and that individual development is influenced by external elements. In addition, every individual lives in a social system and is deeply engaged in systems at multiple levels. Despite their ever-changing relationships, the systems maintain a dynamic equilibrium [10], [19]. [20]. Ecological systems theory uses systems as units, discussing the interactive relationship between human behavior and the environment. These systems can be divided into five levels, in ascending order: individuals, micro-systems, organizations, localities, and macro systems [20], as shown in Fig. 1.

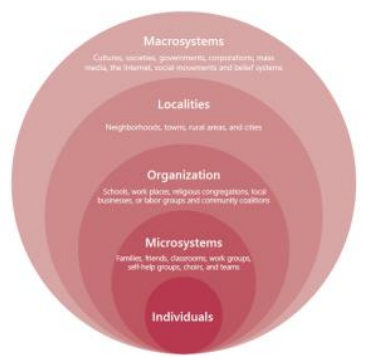

Fig. 1. Diagram of ecological systems in community psychology, redrawn from [20].
One of the objectives of social design is to solve social problems. However, social problems seldom exist independently in a given ecological system, related to the economy, education, medical care, politics, and other constituencies, often lie behind these problems. Hence, the problems of social design involve ecological levels on a large and complex scale [20]. Normally, people work out a solution once they see a problem, but applying such intuitive thinking at a single level may simply address the tip of a much larger iceberg. The advantage of ecological systems theory is that it can integrate interventions at multiple levels, thus exerting a greater influence [19].

While fulfilling social needs, design must also take into account various issues caused by social systems [1], [15]. Ecological systems theory enables researchers to examine the influence of complex interactions between different ecological levels. Evaluating social problems comprehensively [21], by incorporating them into the overall socio-ecological system, can facilitate the understanding of social needs.

\section{B. Process of Social Design}

Designers tend to use the double-diamond model when designing a product or service. The UK Design Council divided the design process into four phases, known collectively as "4D:" discover, define, develop and deliver. The design process entails two rounds of divergence and convergence thinking [22].

The first round is called "the stage of knowing;" it includes the phases of discovery and definition. Designers gain insights and discover new opportunities through empathy. The second round is the stage of doing, which includes the phases of development and delivery. Quick testing is carried out through prototyping, to adhere closely to the users' actual needs [22], [23].

Anand and Haag guided university students to addressing the problems of child education in rural areas [15]. The design practice in this project was based on the double diamond model. However, this model is not fully applicable to every project, as interdisciplinary cooperation, research questions, design issues, and field characteristics must be weighted differently, based on the specific characteristics of each project [2]. Eventually, the DCI was proposed, as a revised design-process model, to offer a method of studying design thinking in relation to a social issue.

The DCI technique achieves a deeper convergence of complex social issues, matches the nature of social design, and facilitates a more comprehensive evaluation of cases. Due to the complexity of social systems and the difficulties inherent in the problem-definition phase, there is a great need for adjustments to the double diamond model within this framework. However, as social design encompasses a wide range of social aspects [22], [24], there is an inter-correlation among these aspects; based on the characteristics of social design, the DCI technique proposes concepts that are different from those of the double diamond model and of referential value to this study. As there is yet to be any clear definition of the procedure or structure of the DCI method, this study has adopted the double diamond model to provide references for course analysis. 


\section{Social Innovation Network}

In traditional education, the teacher is the provider of knowledge. However, social problems necessitate continuous interdisciplinary and inter-organizational conversations [25], in order to innovate new design thinking. Social-design education is no longer limited to teachers who act as knowledge transmitters and students who act as knowledge recipients. When it comes to innovative ways of teaching experiential learning, teachers can move between the four roles of facilitator, coach, evaluator, and subject expert, in accordance with the nature of the course. There are also nine different learning processes, which correspond to students learning activities [13], as shown in Fig. 2.

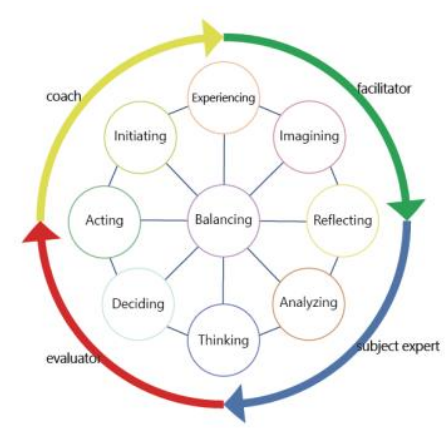

Fig. 2. The experiential learning cycle of the four teaching roles and nine student learning processes, redrawn from [13].

The past narrow mindset toward teaching and learning is evolving into multifaceted forms. The SIN model has been adopted by the U.S. organization, Design for America (DFA), to train social design facilitators. It organizes community partners, project teams, mentors, and studio leads [9], enabling interdisciplinary professionals to come together. Based on the scale of each project, SIN supports three types of activities - project-based social design, student-led studios, and networked community-development improvement [9].

The case investigated here was a university design education program. Although DFA is an organization that exists outside the tertiary education system, using a slightly different operating model than the universities, its teaching style and curricular personnel are both underpinned by interdisciplinary teams. As interdisciplinary knowledge and thinking support the needs of social-design education, it is worth incorporating SIN into any curricular case study. The present study therefore uses SIN to explore the essential elements of social-design education.

\section{Summary}

To sum up, the above discussion shows that social-design education should possess the three characteristics. The first characteristic relates to design practices; social-design education must incorporate a DCI-based design process with design-practice attributes. Achieving a deeper convergence with social issues will ensure that designs adhere closely to complex social conditions, correspond to the nature of social design, and facilitate a more comprehensive evaluation of cases. Second, problem evaluation is also essential; ecological systems theory can situate problems within a comprehensive socio-ecological system for evaluation, enabling students to perceive the relationship between design and society from a wider perspective. The third characteristic is interdisciplinary cooperation. Social-design education requires interdisciplinary cooperation; SIN can integrate, organize, and share different types of background knowledge and thinking among members of interdisciplinary teams.

\section{CASE Study AnAlysis OF THE "Social Design" COURSE}

\section{A. Case Overview}

Currently, the typical problems faced by rural communities in Taiwan include population aging, the outflow of youth labor, insufficient infrastructure, the lack of hard and soft infrastructure, and stunted economic growth [26]. National Yunlin University of Science and Technology (YunTech) is a national university in an agricultural county in Taiwan. Faced with an old-age dependency ratio of up to $18 \%$ [27] and the problems caused by an aging society, university teachers and students must leverage their own specialties to realize the socially responsible design through university-level design education.

The course discussed here is called "Social Design." It explores and arranges hands-on participation in design practices by engaging with the design profession and integrating interdisciplinary expertise. The goal is to help students appreciate the social influence of design. This innovative teaching plan, based on the concept of social design, was a four-month elective program offered by the Research Institute of the College of Design, YunTech from September 2017 to January 2018. A total of 22 Master's and doctoral students from the College of Design enrolled. The course was jointly taught by three teachers from different professions: design, information management, and corporate management. They adopted an interdisciplinary perspective to provide a more comprehensive range of course content The Chief of Kutou Village was a collaborating community partner and the cross-field characteristics of this course enabled students to engage directly with actual community issues.

The Kutou Village community was selected as the field of practice for the "Social design" course. It is a typical agricultural community, located to the east of the city center of Huwei Township, Yunlin County, Central Taiwan (as shown in Fig. 3). The population is 939 and the local religions include Taoism and Buddhism. The size of Kutou Village is approximately 1.82 square kilometers. As it lies on the alluvial fan of the Zhoushui River, Kutou Village is situated on flat terrain. It has a subtropical climate with an average annual temperature of $22.6^{\circ} \mathrm{C}$ and an average annual rainfall of 1028.9 millimeters [28]. The locations of public spaces and manufacturers are shown in Fig. 3.

From the vantage point of agriculture, the community enjoys a favorable climate and good soil; it also has a substantial amount of arable land. As a result, most local residents are engaged in agriculture. The main crops grown in this area include garlic, corn, peanuts, and rice. In terms of manufacturing, Huwei Township is the heart of Taiwan's towel manufacturing industry and Kutou Village specializes in manufacturing towels in bulk, using original equipment (OEM). A large-scale OEM towel factory has recently been 
transformed into a sight-seeing destination. Most local households are engaged in the OEM production of towels. In addition, the community has a kitchen knife factory, a scallion pancake factory and a Shanghai hairy crab farm, among other traditional industries. As for the service industry, due to the local problem of demographic aging, there is also a day-care center. In terms of public spaces, there is a community center and a canteen for elderly people, which provides discussion and dining spaces for elderly residents. The parks and green spaces have been built by renovating dirty and unsightly locations and old houses. However, the community still has derelict houses and abandoned spaces.

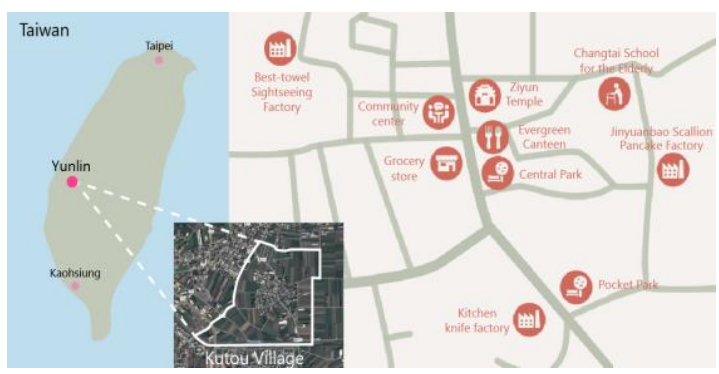

Fig. 3. Kutou village geography and community map.

During the course, students were guided by the teacher to explore problems in different fields and to formulate solutions, with the help of local specialists. This structure allowed the students to fully leverage their specialized design knowledge to engage in and address key issues. The "Social Design" course drew on a diverse range of teaching methods, including knowledge introduction, four to six rounds of field studies, three workshops, and classroom discussions and reflections.

In terms of knowledge input, the teacher took on the role of a subject expert, teaching topics such as shared economy, social innovation, and social design. Outside lecturers were also invited to explore the subjects of long-term care and systems thinking. The first round of field studies was guided jointly by the Chief of the Village and the course teacher; the remaining rounds were initiated by groups of students, who visited the field in accordance with their needs. Each group engaged in between four and six field studies, which allowed them to gain a complete understanding of specialized fields through research, as shown in Fig. 4.

Three workshops were held throughout the course. The first was a one-day makers' workshop organized in YunTech and attended by the enrolled students; it taught the students about different tools and how to apply them to design and development projects. The second was a one-day revitalization workshop held in Kutou Village with 13 local residents; it gave the students a chance to talk with local residents directly and to convert thoughts that were still in the imagination phase into ideas with potential to meet actual needs, as shown in Fig. 5. The third was a two-day participatory design workshop also held in Kutou Village. Eight local residents attended this event, which gave students a chance to draw on the knowledge of stakeholders to retain, add to, or modify the evaluated needs in our research, as shown in Fig. 6.

The teacher evaluated the performance of each student in the classroom discussions and reflections, providing feedback after knowledge-input sessions. The students developed design proposals and analyzed the problems through discussions. The course included problem-analysis based on ecological systems theory, providing feedback on the proposals and workshop reflections, as shown in Fig. 7.

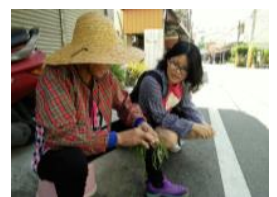

Fig. 4. Student undertaking independent field study.

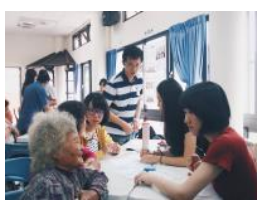

Fig. 5. Revitalization workshop.

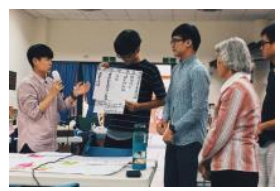

Fig. 6. Participatory design workshop.

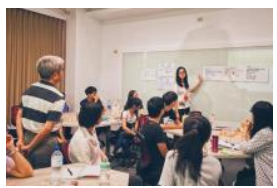

Fig. 7. Lecture in the form of a group discussion and presentation.

\section{B. Analysis of Course Activities}

Because of the diversity of teaching methods used, the course extended beyond the traditional classroom to engage with the community surrounding the university. Along with the students and teacher, community residents and other stakeholders with an interest in social problems also participated in this course. As these innovative teaching methods took a bold step away from tradition, both the design practices and the problem evaluation of the case are worth discussing.

This study matches the above models in approaching a case in its present stage. The steps are as follows: 1) the "Social Design" course is dissected, and the units are assigned simple names that describe the course content; 2) the participants and fields are listed to examine how stakeholders are engaged to provide interdisciplinary cooperation; 3) the experiential learning cycle is aligned with the course content. A self-assessment tool for measuring the educator's role is used to validate the teacher's classroom role-playing; 4) the case is correlated using the four phases of the double diamond model to examine how design practices have been implemented in the case. Using these four steps, course activities are analyzed and organized (see Fig. 8).

After aligning the course units with the four phases of the double diamond model, the table includes blank cells, marking areas that the model has failed to interpret. These represent the reflections and analysis involved in the learning activities. Although social-design education is modelled on design practices, the introduction of new knowledge and reflective learning are important stages of innovative teaching. 
In particular, many reflective learning activities were arranged around case units, to train students to reflect on previous proposals when making new ones. This is a limitation of the double diamond model when it comes to social-design education.

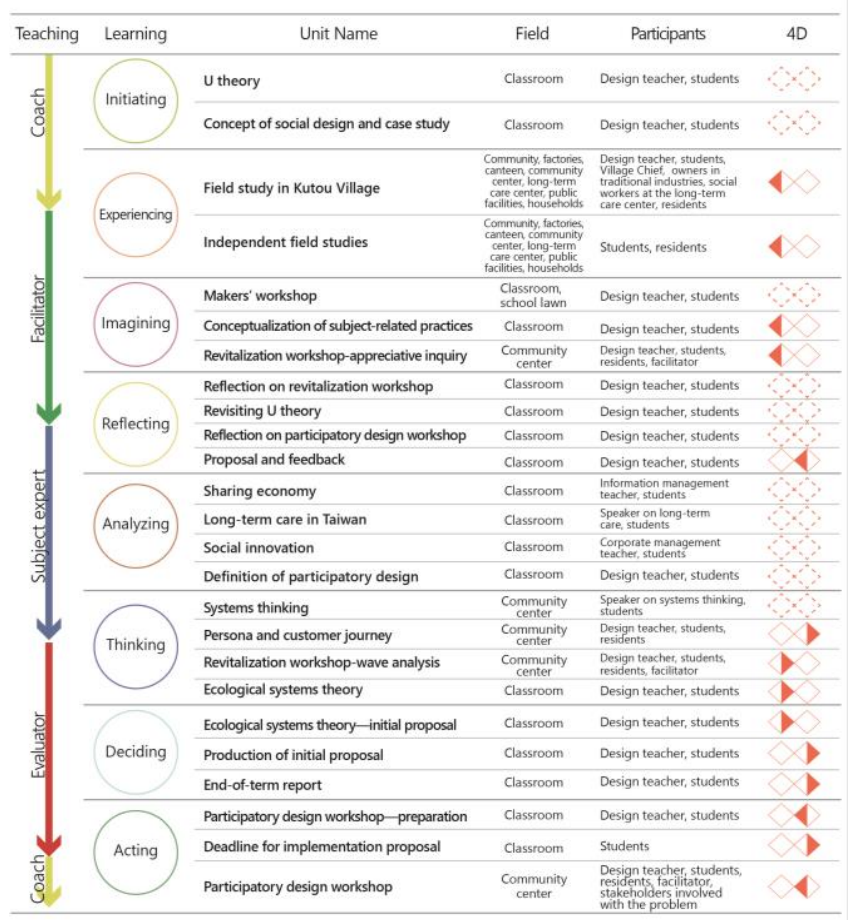

Fig. 8. Analytical table of course activities.

According to the participants' own analysis, stakeholders such as the Chief of Village, community residents, and business owners in traditional industries took part in the learning activities of experiencing, imagining, thinking, and acting. They cooperated in seeking solutions to problems, rather than letting the students design proposals all by themselves. In terms of interdisciplinary teaching, the teachers from the fields of corporate and information management served as subject experts in the learning activities. This enabled the students to apply interdisciplinary knowledge to their subsequent designs, to solve problems during analytical activities.

The teaching field of this course extended from the classroom into the community, encompassing factories, the long-term care center, households, and community centers; the scale of problems broadened and expanded accordingly. In addition, ecological systems theory was used to evaluate problems, giving the students a multilayered understanding of problems during thinking and deciding activities.

\section{CONCLUSION}

The case in this study broke through the boundaries of traditional design education by using both interdisciplinary teachers and cross-field participants. It is worth noting that social systems display the characteristics of dynamic change. This affects problem-solving strategies, as course participants and fields change. The present study concludes that social-design education requires six essential elements:

1) To train students to propose innovative solutions to problems;

2) To analyze problems comprehensively, on the scale of the socio-ecological system;

3) To solve problems using interdisciplinary knowledge and understanding;

4) To engage in the problem-solving process with people who have experienced the problem;

5) To ensure that students can achieve reflective learning during the problem-solving process;

6) To guide students in recognizing the "organic" nature of social-design problems, in which levels of stakeholder participation affect problem-solving decisions, as social systems constantly change.

The findings of this study may serve as a teaching reference for university teachers. With further investigation into individual case experiences, we hope to explore more possibilities in the curricula, to inspire creativity in social design, and to implement social responsibility of designer in university.

\section{CONFLICT OF INTEREST}

The authors declare no conflict of interest.

\section{AUTHOR CONTRIBUTIONS}

Hui Hsin Cheng conducted the research and wrote the paper; Wen Hui Chou gives advise to the paper.

\section{REFERENCES}

[1] V. Papanek, Design for the Real World, 1971, Taipei City: Wu-Nan Book.

[2] C. F. Lee, "Approaches to product design for the elderly," Journal of Design, 2008, vol. 11, no. 3.

[3] N. Whiteley, Design for Society, 1997, Reaktion Books.

[4] V. Margolin and S. Margolin, "A "social model" of design: Issues of practice and research," Design Issues, 2002, vol. 18, no. 4, pp. 24-30.

[5] A. Fuad-Luke, Design Activism: Beautiful Strangeness for a Sustainable World, 2013, Routledge.

[6] M. Steen, "Organizing design-for-wellbeing projects: Using the capability approach," Design Issues, 2016, vol. 32, no. 4, pp. 4-15.

[7] S. Wildevuur et al., Connect: Design for an Empathic Society, 2013, BIS Publishers.

[8] S. M. A. A. Tabrizi and A. S. Ergenoglu, "Monitoring model for universal design in educational facilities," presented at 5th Cyprus International Conference on Educational Research, 2016.

[9] M. W. Easterday, E. M. Gerber, and D. G. R. Lewis, "Social innovation networks: A new approach to social design education and impact," Design Issues, 2018, vol. 34, no. 2, pp. 64-76.

[10] J. F. Sallis et al., "An ecological approach to creating active living communities," Annu Rev Public Health, 2006, vol. 27, pp. 297-322.

[11] J. Dalton, M. Elias, and A. Wandersman, Community Psychology: Linking Individuals and Communities, Belmont, Calif.: Thomson Wadsworth, vol. 2, 2007.

[12] A. Noland and K. Richards, "The relationship among transformational teaching and student motivation and learning," Journal of Effective Teaching, 2014, vol. 14, no. 3, pp. 5-20.

[13] A. Noland and K. Richards, "Servant teaching: An exploration of teacher servant leadership on student outcomes," Journal of the Scholarship of Teaching and Learning, 2015, vol. 15, no. 6, p. 16.

[14] A. Y. Kolb et al., "On becoming an experiential educator: The educator role profile," Simulation \& gaming, 2014, vol. 45, no. 2, pp. 204-234.

[15] K. Anand and J. Haag, "A framework for teaching design for social impact," presented at Designing Design Education for India Conference, 2013, March, Pune: India Design Council.

[16] S. Bowen et al., "The value of designers' creative practice within complex collaborations," Design Studies, 2016, vol. 46, pp. 174-198.

[17] O. D. Kolawole and K. Ajila, "Driving local community transformation through participatory rural entrepreneurship development," World Journal of Entrepreneurship, Management and Sustainable Development, 2015, vol. 11, no. 2, pp. 131-139.

[18] A. Jansson, "Mediatization as a framework for social design: For a better life with media," Design and Culture, 2018, pp. 1-20. 
[19] U. Bronfenbrenner, "Toward an experimental ecology of human development," American psychologist, 1977, vol. 32, no. 7, p. 513.

[20] L. McCormack et al., "Improving low health literacy and patient engagement: A social ecological approach," Patient Education and Counseling, 2017, vol. 100, no. 1, pp. 8-13.

[21] S. L. Pittenger, T. Z. Huit, and D. J. Hansen, "Applying ecological systems theory to sexual revictimization of youth: A review with implications for research and practice," Aggression and Violent Behavior, 2016, vol. 26, pp. 35-45.

[22] D. Council, Eleven Lessons: Managing Design in Eleven Global Brands, 2007, London, UK: The Design Council.

[23] T. Brown, Change by Design: How Design Thinking Transforms Organizations and Inspires Innovation, 2010, Taipei City: Linking Publishing.

[24] D. Bell and M. Nusir, "Co-design for government e-service stakeholders," presented at 50th Hawaii International Conference on System Sciences, 2017, Hawaii.

[25] T. Irwin, "Transition design: A proposal for a new area of design practice, study, and research," Design and Culture, 2015, vol. 7, no. 2, pp. $229-246$

[26] S. Y. Lin, "The comparison of community collaboration policies in taiwan from the perspective of collaborative governance - The case of the comprehensive community development and rural rejuvenation," Thesis of National Cheng Kung University Department of Urban Planning, 2017, pp. 1-178.

[27] Department of Statistics of the Ministry of the Interior. (December 2017). Latest Statistical Indicators. [Online]. Available: https://www.moi.gov.tw/stat/chart.aspx
[28] Yunlin County Government. (October 2017). Geography Introduction. [Online]. Available: https://www.yunlin.gov.tw/content/index.asp?m=1\&m1=3\&m2=14

Copyright $(92019$ by the authors. This is an open access article distributed under the Creative Commons Attribution License which permits unrestricted use, distribution, and reproduction in any medium, provided the original work is properly cited (CC BY 4.0).

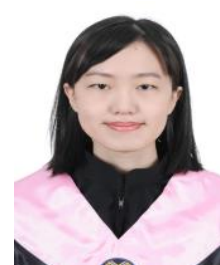

Hui Hsin Cheng was born in Tainan, Taiwan. Cheng is a master student at the Department of Digital Media Design in National Yunlin University of Science and Technology in Yunlin county in Taiwan. In 2017 Cheng got a bachelor of science from the Department of Information Learning Technology in National University of Tainan.

She is one of the members of Innovation Media Design Research laboratory in Yunlin.

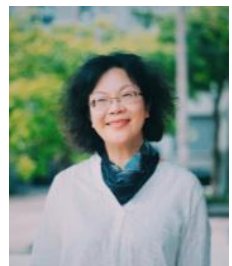

Wen Huei Chou is a professor at the Digital Media Design Department in National Yunlin University of Science and Technology in Taiwan. Chou holds a doctoral degree from Swinburne University of Science and Technology, in Australia.

She is a director at Innovation Media Design Research laboratory. She dedicates herself in the field of social design for a long time, and has developed a unique and systematic strategy of facilitating workshops. 